\title{
LA PRENSA Y LA PARTICIPACIÓN ESTUDIANTIL EN LA NEGOCIACIÓN DEMOCRÁTICA DE ESPAÑA (1978-1982)'
}

DOI: http://dx.doi.org/10.1590/2236-3459/76998

\author{
Tamar Groves \\ MaInmaculada Pedrera Rodríguez \\ Universidad de Extremadura, Cáceres/Extremadura, España
}

$\cos 80$

\begin{abstract}
Resumen
En el presente artículo analizaremos uno de los movimientos sociales más destacados en la lucha antifranquista durante el periodo de Transición española hacia la democracia, el movimiento estudiantil. Nos situaremos en su vuelta a la acción a lo largo de los años 70, donde formó parte de las negociaciones en las primeras políticas democráticas. Nos centramos en la participación de este movimiento en contra del Proyecto de Ley de Autonomía Universitaria, la reforma propuesta por el legislativo de la Unión de Centro Democrático (UCD), como parte de una movilización social más amplia que trató de asentar las bases de la democracia española. Para ello, estudiaremos las noticias publicadas en El País, uno de los periódicos españoles que ayudaron al proceso democrático acercando la actualidad a la sociedad. Este periódico, considerado por muchos el periódico de la Transición, fue identificado socialmente con el cambio político que se estaba viviendo, favorecido por un oportuno nacimiento una vez finalizada la dictadura del General Franco. La selección y análisis de las noticias publicadas en este momento histórico, nos ofrece una visión de la imagen social del movimiento estudiantil como un actor que luchaba por cambiar la universidad como parte de un cambio más amplio que incluía la recuperación de los derechos civiles y el fin de la dictadura. La oposición a la ley fue más relacionada a esta carga política que estrictamente al contenido de la reforma. Asimismo, por el avance del proceso político basado en la negociación entre los partidos, el ideario democrático y educativo del movimiento estudiantil se quedó frustrado.

Palabras clave: movimiento estudiantil, transición española, autonomía universitaria, periódico El País.
\end{abstract}

\section{A PARTICIPAÇÃO DA IMPRENSA E DOS ESTUDANTES NA NEGOCIAÇÃO DEMOCRÁTICA DA ESPANHA (1978-1982)}

\begin{abstract}
Resumo
No presente artigo, analisaremos um dos movimentos sociais mais proeminentes na luta anti-franquista durante o período de transição espanhola para a democracia, o movimento estudantil. Estaremos em seu retorno à ação nos anos 70 , onde foi parte das negociações nas primeiras políticas democráticas. Nós nos concentramos na participação deste movimento contra o Bill da autonomia universitária, a reforma proposta por parte do legislador da União de Centro Democrático (UCD), como parte de um movimento social mais amplo, que tentou lançar as bases de Democracia espanhola. Para fazer isso, estudaremos as notícias
\end{abstract}

\footnotetext{
${ }^{1}$ El artículo es parte del trabajo desarrollado por el grupo de investigación Ágora de Educación (Universidad de Valladolid, España) (http://www.agoradeeducacion.com).
}

\begin{tabular}{|l|l|l|l|l|r|} 
Hist. Educ. (Online) & Porto Alegre & v. 22 & n. 54 & jan./abr. 2018 & p. 91-112
\end{tabular}


publicadas em El País, um dos jornais espanhóis que ajudaram o processo democrático, trazendo notícias atualizadas para a sociedade. Este jornal, considerado por muitos o jornal da Transição, foi identificado socialmente com a mudança política que estava vivendo, auxiliado por um nascimento oportuna uma vez que a ditadura do general Franco. Seleção e análise publicada neste momento histórico, notícias nos oferece uma visão da imagem social do movimento estudantil como um ator lutando para mudar a universidade como parte de uma mudança mais ampla, que incluiu a recuperação dos direitos civis e fim da ditadura. A oposição à lei estava mais relacionada com essa carga política do que estritamente ao conteúdo da reforma. Além disso, devido ao progresso do processo político baseado na negociação entre as partes, a ideologia democrática e educacional do movimento estudantil foi frustrada.

Palavras-chave: movimento estudantil; transição espanhola; autonomia universitária; jornal de El País.

\title{
THE PRESS AND THE PARTICIPATION OF UNIVERSITY STUDENTS IN THE DEMOCRATIC NEGOTIATION IN SPAIN (1978-1982)
}

\begin{abstract}
In this article we study the students' movement which played an important role during the late Franco period and the transition to democracy in Spain. We focus our analysis on its return to action in the late 1970s, when it participated in the social negotiations of the first educational policies of the recently established democracy. We look at the struggle of the movement against the draft of the Law of the Autonomy of the University (Proyecto de Ley de Autonomía Universitaria), advanced by the government led by the UCD, the Union of the Democratic Centre party. This struggle was part of a much wider effort to influence the configuration of the young Spanish Democracy. In order to do this, we look at the press coverage of the struggle as it appeared in one of the leading newspapers of the time, El País. This newspaper is considered as The Newspaper of the period of the transition as it actively supported the process, and eventually was identified with the democratization of the country after the death of the dictator, General Franco. This analysis permits us to reconstruct the social image of the students' movement in this historical moment, as one of the social actors which fought for changing the University as part of democratizing the country and recuperating basic civil rights, once the dictatorial period was over. As we show, the opposition to the law, was more related to this political and social struggle than to the actual educational content of the proposed reform. In addition we look at how, as the process of political negotiation advanced, the democratic and educational agenda of the students' movement was mainly left behind.
\end{abstract}

Keywords: students' movementes, spanish transition to democracy, university autonomy, El País.

\section{Résumé}

Dans ce chapitre, nous analyserons l'un des mouvements sociaux les plus importants de la lutte anti-franquiste durant la transition vers la démocratie en Espagne, le mouvement étudiant. Nous nous situerons dans son retour à l'action tout au long des années 70 , où il faisait partie des négociations dans les premières politiques démocratiques. Nous nous concentrons sur la participation de ce mouvement contre le projet de loi d'autonomie des universités, la réforme proposée par le législateur de l'Union du Centre Démocratique (UCD), dans le cadre d'un mouvement social plus large qui a essayé de jeter les bases de La démocratie espagnole. Les étudiants ont lutté pour changer l'université dans le cadre d'un changement plus large qui comprenait la récupération des droits civils et la fin de la dictature. Pour cela, nous allons étudier les nouvelles publiées dans El País, l'un des journaux espagnols qui ont aidé le processus démocratique apportant les nouvelles à la société. Ce journal, considéré par beaucoup comme le journal de la Transition, a été identifié socialement avec le changement politique qu'il vivait, favorisé par une naissance opportune une fois la dictature du général Franco terminée. La sélection et l'analyse publiée en ce moment historique, les nouvelles nous offre une vision de ce journal ont collaboré dans le processus de démocratisation, placé, comme la plupart des publications de l'époque, en régime de la relève par le biais de la réforme.

Mots-clés: mouvement étudiant, transition espagnole, autonomie universitaire, El País journal. 


\section{Introducción}

n diciembre de 1978 la Constitución democrática de España fue ratificada a través de un referéndum, que puso fin, así, a cuarenta años de dictadura y estableció un estado democrático que garantizaba los derechos y los deberes de los ciudadanos. Para muchos especialistas, como para la mayoría de los ciudadanos, este acontecimiento cerró con éxito la transición española hacia la democracia. Sin embrago, para otros, la democratización de España no finalizó con este evento y, en diferentes ámbitos y lugares, continuaba una negociación intensa relacionada con la naturaleza de la recién nacida democracia. (HERRERA, 2017). Determinados sectores, especialmente relacionados con los grandes movimientos sociales, surgidos en los últimos años de vida del dictador, el General Francisco Franco, sintieron cierto rechazo hacia el modelo democrático consolidado en España. Las causas fueron los privilegios otorgados a los partidos políticos en detrimento del protagonismo de los actores sociales colectivos forjados durante la larga lucha por la democracia. (GROVES, 2017; SÁNCHEZ LEÓN, 2010).

En este artículo analizamos uno de los movimientos sociales más destacados en la lucha anti-franquista, la movilización estudiantil. Sin embargo, contrariamente a lo habitual, nuestro análisis se centra en los años caracterizados justamente por su decadencia. En la mayoría de los casos se estudia el fenómeno hasta 1970, debido a la reforma educativa diseñada, entre otros fines, para solucionar el problema universitario (RUBIO MAYORAL, 2005; ÁLVAREZ COBELAS, 2004), o hasta la muerte del dictador, en 1975. (HERNÁNDEZ SANDOICA; RUIZ CARNICER; BALDÓ LACOMBA, 2007). En efecto, entre 1970 y 1975 las universidades ya no eran espacios políticos privilegiados como en épocas anteriores, y el movimiento estudiantil perdió su liderazgo en la oposición anti-franquista. Sin embargo, el movimiento experimentó una vuelta a la acción a lo largo de los años 70, tomando parte en las negociaciones de las primeras políticas democráticas. En este artículo, observamos de cerca la movilización estudiantil tras la promulgación de la Constitución de 1978, centrándonos en su reavivamiento alrededor de la incitativa de reforma de la Universidad ofrecida por la Unión de Centro Democrático (UCD). Terminamos nuestro análisis en 1982, en el momento del cambio en la política educativa tras la constitución del primer gobierno de izquierdas después de la dictadura.

El artículo 27 de la Constitución española, referido a la educación, es un artículo ambiguo que intenta conciliar tanto los principios de la derecha, con respecto a la libertad de educación, como los de la izquierda, relacionados con la igualdad de oportunidades. El resultado, por tanto, es un artículo indeterminado que se puede llenar de contenido según las tendencias del gobierno. (NOGUEIRA, 1988). Esta situación se hizo patente ya durante los primeros gobiernos de la democracia. La UCD, desde un momento muy temprano, empezó a trabajar sobre reformas educativas tanto en la educación universitaria como en la no universitaria para asegurar una legislación acorde con sus principios. La reacción social hacia la legislación educativa, en general, y hacia la propuesta reforma universitaria se encuentran en el centro de este artículo.

Así mismo, a nivel metodológico, y siguiendo el hilo conductor de este monográfico, en nuestro análisis del fenómeno hemos privilegiado la prensa diaria como una fuente histórica. (CAGNOLATI, 2011; HERNÁNDEZ HUERTA; GONZÁLEZ GÓMEZ, 2014; HERNÁNDEZ HUERTA; ORTEGA GAITE, 2015). Más concretamente, en nuestro caso, 
hemos elegido el periódico que está considerado como el diario con mayor influencia durante el periodo de transición, El País. (ALMUIÑA, 2009; BAZÁN, 2015; SUEIRO, 2009; MONTERO; RODRÍGUEZ-VIRGILI; GARCÍA-ORTEGA, 2008). Gracias a su apuesta por ofrecer una sección de opinión potente y una amplia información internacional, contando con numerosas corresponsalías (MARINA, 2012) rápidamente se convirtió en el periódico de mayor ventas e influencia social en España durante la época crucial de la transición democrática. (SEOANE; SUERO, 2004; ALMUIÑA, 2009).

Para localizar las noticias que tratan el tema de la movilización estudiantil y de la reforma relacionada con la autonomía universitaria, hemos utilizado los textos disponibles en la hemeroteca digital del periódico, haciendo búsquedas automáticas con las palabras clave: estudiantes, protesta y autonomía universitaria. Este tipo de búsqueda ofreció una gran cantidad de noticias que fueron reducidas a partir de una revisión manual, primero de los títulos y, segundo, por el contenido de los artículos. Como es bien sabido, las distintas hemerotecas no incluyen necesariamente todas las noticias publicadas y, por tanto, las búsquedas del tipo que hemos realizado están lejos de ser exhaustivas. Así, cabe la posibilidad de que no se hayan localizado todas las noticias relevantes sobre nuestro tema de investigación. Sin embargo, hemos podido localizar suficientes artículos para explorar la representación de las protestas estudiantiles, en general, y las relacionadas con la autonomía universitaria, en particular, de aquella época.

Con el fin de contextualizar la representación de las movilizaciones estudiantiles en El País entre 1978 y 1982, comenzamos este artículo dedicando un apartado al panorama de la prensa española al final de la dictadura y los primeros años de la transición. La naturaleza de la cobertura periodística depende de múltiples factores y, en el caso español, objeto de nuestro interés, se trató de una prensa surgida tras una larga época de control, opresión y censura bajo la dictadura franquista, la cual se encontraba en sus inicios para establecerse como un actor significativo en el nuevo estado democrático. La segunda parte del articulo ubica a los movimientos estudiantiles españoles en los dos contextos más importantes para su desarrollo: la movilización anti-franquista y los movimientos estudiantiles globales de los años 60. El tercer y el cuarto apartados del artículo están dedicados al análisis de la cobertura del periódico El País de la cuestión de la autonomía universitaria y de la movilización estudiantil. El tercer apartado mira de cerca cómo el periódico representaba la iniciativa legislativa de la UCD con respecto a la autonomía universitaria, destacando los puntos más criticados de la reforma. El cuarto apartado del artículo contempla la representación de la movilización estudiantil y sus acciones contra la reforma. Nuestro análisis empieza en 1978 con la aprobación de la Constitución y sigue hasta 1982, con la llegada del partido socialista al legislativo. Se trata, por lo tanto, de la época en la que el gobierno de centro derecha de la UCD, considerado como el heredero de las elites de la dictadura, intentó diseñar el sistema educativo según su ideología e intereses.

En este trabajo se interpreta el movimiento estudiantil en su lucha por la defensa de la autonomía universitaria, como parte de una movilización social más amplia que trata de asentar las bases de la democracia española, entendiendo que la idea de autonomía universitaria que defiende se encuentra influenciada por nuevos movimientos sociales, tanto de sus referentes como de la crítica que realiza a la versión de la democracia occidental existente en el momento. Por lo tanto, a lo largo del trabajo se intenta relacionar 
la lucha estudiantil en España y sus aspiraciones políticas tanto a su contexto global - los nuevos movimientos sociales, como a su contexto más inmediato - las políticas educativas de la UCD. En este sentido el artículo ofrece una nueva mirada del movimiento estudiantil en esta época de negociación democrática, fijándose especialmente en la representación social del fenómeno a través de la prensa.

\section{El País y los medios de comunicación durante la transición}

Con la muerte del dictador Francisco Franco en noviembre 1975, la prensa escrita española, a pesar de salir de una época de casi 40 años de dictadura, presentaba cierta experiencia en cuanto a la libertad informativa. El control de los medios que había ejercido el régimen fue suavizado con la promulgación de la Ley de Prensa e Imprenta de 18 de marzo de 1966, más conocida como la Ley Fraga. Esta ley, aunque instaurada con resistencia por parte del régimen a una apertura total, consiguió ampliar los límites sobre la libertad informativa y de opinión, concediendo cierta apertura hacia la libertad de prensa a través de la eliminación de la censura previa en las publicaciones escritas y la incipiente aparición de ideologías variadas en sus escritos. (MARINA, 2012).

Esta situación ambigua de cierta libertad condicionada seguía en pie tras la muerte del dictador. Oficialmente, la libertad de prensa se instauró el 1 de abril de 1977 con la promulgación de un Decreto Ley que garantizaba el derecho de todos los ciudadanos a recibir una información veraz y la libertad de expresión, dentro de los márgenes establecidos en esta normativa. Esta reforma fue posible gracias a la ley de reforma política de enero 1977 que terminó con el sistema político de la dictadura y permitió, a nivel jurídico y político, avanzar hacia la democracia. La promulgación del Decreto Ley de abril, que garantizaba la libertad de la prensa, despejó el camino a la celebración con garantía de las primeras elecciones democráticas de junio de ese mismo año, evitando, con ello, la desacreditación del proceso electoral en el caso de mantener las limitaciones a la prensa. (MONTERO et al., 2008). Las conquistas alcanzadas con respecto a la libertad de prensa fueron ratificadas por la Constitución Española en 1978, culminando el proceso de libertad de prensa presente en la actualidad.

El final del régimen aumentó el panorama de los medios de comunicación escritos con el mantenimiento de la prensa tradicional, de corte conservador, que realizaba publicaciones durante el régimen y con el nacimiento de otra nueva, de marcado corte democrático, quienes se beneficiaron de la ausencia de relación con él. Unos y otros, en su mayoría, colaboraron en el proceso democratizador, posicionándose en la sucesión del régimen por la vía de la reforma. Entre ellos, algunos anteriores al franquismo, se pueden destacar ABC, Ya, La Vanguardia o El Correo Español-El Pueblo Vasco. Aquellos, producto de la dictadura fueron Pueblo, Arriba y El Alcázar, propiedad del Estado. Y entre los periódicos de nueva creación se encontraban El País, Diario 16 y los nacionalistas Avui, Deia y Egin, posicionados en el centro-izquierda y el nacionalismo.

Aquellos diarios más tradicionales, a excepción de El Alcázar, que presentaba una ideología de extrema derecha, fueron adaptándose a las nuevas condiciones democráticas que se iban instaurando en el país, y adoptando, por tanto, posturas políticas más acordes con los nuevos tempos. (BARRERA, 1997). Unos y otros aunaron objetivos, la consecución de un régimen democrático donde se legalizasen los partidos políticos, incluido el comunista, y se celebraran unas elecciones libres. (MONTERO et al., 2008). De esta 
manera, la prensa española apoyó al gobierno y oposición a fin de conseguir el éxito del proceso, además de introducir, paulatinamente, en sus páginas valores democráticos como convivencia, consenso, libertades civiles, amnistía, autonomía para las regiones, etc. (BARRERA; ZUGASTI, 2001). Sin embargo, cada uno de los diarios fue actuando según su propia tendencia, así los de reciente creación, libres de trabas y sin compromisos con la situación anterior, pusieron mayor énfasis en su apoyo a la democracia.

El más destacado de ellos fue, sin duda, El País. Su inicio se remonta a enero de 1972 cuando el editor José Ortega Spottorno y los periodistas Carlos Mendo y Darío Valcárcel, compañeros en el diario $A B C$, crearon la Promotora de Informaciones S. A. (PRISA). Su finalidad era lanzar al mercado un diario liberal, europeísta y moderno, contrario tanto al régimen como al marxismo (SUEIRO, 2009), el cual no se hizo realidad hasta 1975 con la inscripción de PRISA en el Registro de Empresas Periodísticas tras varios años de silencio administrativo que retrasó su aparición. El periódico salió a la luz, por primera vez, el 4 de mayo de 1976, una vez fallecido el dictador, lo que le posibilitó presentarse en sociedad libre de ataduras del régimen. Así, la España del momento lo identificó con el cambio político que se estaba vivendo. (ZUGASTI, 2007). Ambos factores, unidos a una cuidadosa selección de los profesionales y a una potente organización empresarial, fueron la base de un pronto éxito, convirtiéndose, a los seis meses de su nacimiento, en el primer matutino de Madrid en ventas. (SUEIRO, 2009).

El periódico construyó un discurso ideológico progresista que le acercó a la oposición, fundamentalmente al Partido Socialista Obrero Español (PSOE), rechazando las propuestas de personajes provenientes del régimen como el gobierno de Arias Navarro y Manuel Fraga, y muy reticente ante las actuaciones del entorno de Adolfo Suarez. (MARINA, 2012). Desde su primera editorial, Ante la reforma, muestra incredulidad sobre las intenciones de reforma política que venía anunciando el gobierno de Arias Navarro en su proyecto aperturista. El periódico se pronunció a favor de los valores laicos, posicionándose en una postura progresista o de izquierdas en temas sociales como la regularización del matrimonio civil o divorcio, los anticonceptivos, la despenalización del aborto, la cohabitación fuera del matrimonio, la secularización de la enseñanza o la eliminación del estigma de la homosexualidad.

Desde su inicio, El País se presentó como un diario formalmente serio, con una sección de opinión potente en la que participaban muchos intelectuales, sin corte sensacionalista, aunque no elitista, dirigido al público de la calle. Primó la intención de Juan Luís Cebrián, en contra de las pretensiones de Ortega Spottorno quien pretendía elaborar un diario destinado a la élite. En noviembre de 1975 y manteniéndose en el puesto hasta 1988 fue nombrado director del periódico el periodista Juan Luís Cebrián, redactor jefe en el diario Pueblo y subdirector en Informaciones. El nuevo director presentaba ideas liberalprogresista, demócrata, europeísta convencido y laico, cercano al anticlericalismo. (ZUGASTI, 2009). Junto a él, fue nombrado como Consejero delegado el empresario editorial Jesús Polanco quien tomó las riendas del nuevo proyecto desde el punto de vista empresarial. Estos nombramientos fueron transcendentales en el desarrollo del diario, el cual obtuvo desde el principio buenos resultados económicos y en ventas, consolidándose como el diario de la Transición.

El grupo humano, cuidadosamente seleccionado, dio lugar a una redacción joven, con una media de 29 años, ideológicamente posicionados a la izquierda o extrema 
izquierda. Muchos colaboradores eran

[...] escritores e intelectuales anticlericales, ateos o agnósticos, como Fernando Savater, Francisco Umbral o Rafael Sánchez Ferlosio, que abordaban todo tipo de temas y de vez en cuando se despachaban con artículos provocadores. (SUEIRO, 2009, p. 160).

Desde que se constituyó la promotora PRISA hasta la aparición del periódico, tres veces hubo ampliación del capital, pasando de ser tres los primeros titulares de acciones, sus creadores, a cerca de 400 personas en la ampliación de 1975. Entre los propietarios, provenientes de la burguesía ilustrada del momento, se encontraban Manuel Fraga y José $\mathrm{M}^{\mathrm{a}}$ de Areilza, además de empresarios, banqueros, diplomáticos, ingenieros, escritores, médicos, altos funcionarios, artistas o catedráticos de universidad. (SEOANE; SUEIRO, 2004). Se trataba de un grupo de liberales y aperturistas, provenientes de una amplio espectro político e ideológico. El desacuerdo con la línea editorial y el tratamiento dado a temas sociales y eclesiásticos, dio lugar a un malestar y discrepancia entre una parte de los accionistas más conservadores del periódico con la dirección-redactores que elaboraban el rotativo.

Las discrepancias sobre la responsabilidad de la autoría de la línea editorial siempre estuvieron presentes. En octubre de 1977 dimitió el subdirector Darío Valcárcel por sus desavenencias con el director sobre el encauzamiento del periódico y la supervisión directa por parte de los accionistas a la redacción. El apoyo de Polanco a Cebrián forzó su dimisión.

El grupo de promotores liberales cercanos a Ortega caracterizados por ser católicos, practicantes de costumbres conservadoras, esperaban del diario que fuera de "derecha civilizada" (SUEIRO, 2009), calificaban al periódico de radical, con un tratamiento de temas muy progresista y en sintonía con la izquierda eclesiástica. Las divergencias en el consejo de dirección y juntas de accionistas entre 1978 y 1983 dio el éxito a CebriánPolanco, la ruptura con una sección de promotores conservadores y la dimisión de consejeros por disconformidad con la línea del periódico, con una venta de sus acciones.

Fue el tratamiento vanguardista persistente de la realidad del país en su línea editorial la que en estos momentos permite sumergirnos a través de sus publicaciones y analizar elementos relevantes de la transición, entre ellas el movimiento estudiantil, objeto de estudio en estas líneas.

\section{Los movimientos sociales de los estudiantes: entre la protesta contra el franquismo y la movilización estudiantil transnacional}

Los Global Sixties o los Long Sixties son algunos de las denominaciones que surgieron para hablar del cambio en las relaciones entre sociedades y estados a partir de los años 60. Los investigadores están de acuerdo que se trataba de un fenómeno global con una gran variedad de expresiones locales y nacionales, que duró mucho más allá de los años 60. En los últimos años, se observa un mayor número de trabajos que se esfuerzan en analizar la manera en la que las olas transnacionales de ideas, practicas e interpretaciones moldearon la protesta social en diferentes partes del mundo. (HILWIG, 2009; KLIMKE, 2011; HOEFFERLE, 2012). Entre las dimensiones que separan esta concurrencia de movilizaciones a otras anteriores hallamos, primero, la expansión de los 
temas que se encontraban en la base de las protestas. El enfoque tradicional sobre demandas de los derechos de los trabajadores o el aumento salarial, asociados a la lucha de la clase obrera, se diluyó con el surgimiento de temas relacionados con identidades y la vida cotidiana. Movimientos como el feminismo, el ecologista o el pacifismo lucharon por sus espacios dentro de las democracias occidentales. (MELUCCI, 1985).

Otra característica de esta nueva ola de movilizaciones sociales, y relacionada con el rasgo anterior, es su crítica generalizada hacia la lógica política de la democracia occidental. Los nuevos movimientos sociales ofrecieron un modelo democrático alternativo a las democracias representativas en el cual los ciudadanos deberían participar activamente en los debates y la articulación de las políticas que afectaban a su vida cotidiana. Las protestas surgieron contra la idea de una toma de decisiones realizadas desde las altas esferas de la política, reivindicando que el proceso de toma de decisiones que afectan a la vida cotidiana de los ciudadanos debería llevarse a cabo de la manera más cercana posible a éstos y a sus circunstancias. (DELLA PORTA; DIANI, 2006).

Las movilizaciones sociales en España se desarrollaron en un contexto radicalmente diferente a otros contextos más identificados con el concepto de los 60, como el caso norteamericano, francés o italiano. Contrariamente a estos casos que representan unas democracias maduras, en la España de los sesenta todavía regía la dictadura de Franco, uno de las ultimas reliquias del fascismo del primer tercio del siglo XX. Aún existen debates sobre si se puede llamar fascista al régimen franquista incluso en sus orígenes, pero nadie discute que, hasta cierto punto, adoptaba muchas de sus características en sus primeros años. Sin embrago, a partir de los años 60 la dictadura franquista se suele caracterizar como un régimen autoritario dado el gran esfuerzo realizado para de dejar atrás el discurso fascista y adoptar una fuente de legitimidad menos bélica, basada en la eficacia y la modernización. (LINZ, 2000; SAZ, 2004). Incluso intentó utilizar la paz social para justificar la legitimidad de la dictadura. Esto no significa que no se tratara de un régimen opresor que limitaba los derechos ciudadanos, y donde cualquier manifestación de idea políticas libres era castigada duramente. El contexto del surgimiento de los movimientos sociales en España se caracterizó, por tanto, por la ausencia de los derechos civiles más básicos como la asociación, la asamblea, el voto o la libertad de expresión.

La ola de protesta social contra el franquismo surgió al final de los años 50 . En esta época los brotes de movilización eran cortos y se desarrollaban en focos bastante aislados. Sin embargo, esta época representa el principio de una etapa de movilizaciones que se expandió gradualmente a lo largo de los años 60, llegando a su cima en los 70 y descendiendo a lo largo de los 80. Dos de los primeros focos de movilización en esta época tan temprana fueron los trabajadores y los estudiantes, representantes de la vanguardia de la movilización social que se iba extendiendo a muchos más sectores. Los trabajadores se movilizaron creando su propio sindicato semiclandestino, las Comisiones Obreras (CCOO) que funcionó dentro del sindicato vertical del régimen. (RUIZ GONZÁLEZ, 1994; DOMĖNECH SAMPERE, 2008). Se considera que sus prácticas y discurso se iban extendiendo a otros sectores, de manera que a lo largo de los 60 y 70 vemos su influencia en los barrios, entre profesionales, en los movimientos regionalistas, etc.

El segundo foco temprano y destacado de movilización social bajo el franquismo fueron los estudiantes. Su protesta abierta empezó en 1956, pero fue a partir de mediados de los años 60 cuando las universidades españolas se convirtieron en focos de continuo 
conflicto. Los estudiantes de clase media obligaron al régimen a deshacer su propio sindicato estudiantil, reemplazándolo por sus propias organizaciones. Los estudiantes lucharon por cambiar la universidad como parte de un cambio más amplio que incluía la recuperación de los derechos civiles y el fin de la dictadura. (HERNÁNDEZ SANDOICA; RUIZ CARNICER; BALDÓ LACOMBA, 2007). Existe un consenso generalizado sobre la idea de que los estudiantes, a pesar de no llegar a poner al régimen en peligro, llegaron a forjar y difundir una subcultura de disidencia que sobrepasó los límites de la universidad llegando a la sociedad en general. (MARAVALL, 1978; GONZÁLEZ CALLEJA, 2009).

La dinamización del movimiento estudiantil en España estuvo ligada al repertorio innovador ensayado en las universidades norteamericanas y europeas a partir de 1964 . (GONZÁLEZ CALLEJA, 2009, p. 318). Los estudiantes en Berkeley protestaron contra la prohibición de actividades extrauniversitarias, mientras los estudiantes del Freie Universität en Berlín criticaban, entre otras cosas, la burocratización de la gestión académica. (GONZÁLEZ CALLEJA, 2009, p. 318-319). El número de estudiantes a nivel mundial aumentó un 60 por ciento a lo largo de los años sesenta, siendo los movimientos del 68 los que impugnaron su función como mecanismo de cooptación de la sociedad capitalista. Estudiantes de 50 países siguieron estos ejemplos y protestaron contra la universidad burocratizada y alienante, exigiendo libertad para desarrollar actividades políticas dentro de los Campus. El caso de Francia destacó por la alianza con el ámbito industrial y su clara expresión de voluntad de acción directa de carácter antiparlamentario. La protesta se fragmentó eventualmente, diluyéndose, sin embargo, dejó patente que el capitalismo liberal dominante tenía espacios de resistencia cultural donde se adoptaron valores como la tolerancia, la libertad o el igualitarismo. (GONZÁLEZ CALLEJA, 2009, p. 318-320).

En el contexto español los especialistas que han profundizado en la movilización estudiantil sustentan que mientras el núcleo duro de los militantes no se ajusta a las características de los nuevos movimientos sociales, relacionándose más con un modelo tradicional de militancia política, sí se puede encontrar coincidencias con los nuevos movimientos sociales entre la mayoría pertenecientes al segundo y tercer estrato de la actividad. (CARRILLO-LINARES, 2008, p. 595). Los movimientos españoles adoptaron los métodos empleados en otros contextos como parte de la lucha para encontrar la finalidad del estudiante en la sociedad contemporânea. (ÁLVAREZ COBELAS, 2004, p. 343).

El movimiento estudiantil en España surgió en la mitad de los años 50, pero llegó a su gran logro con la caída del sindicato de estudiantes del régimen, el Sindicato Español Universitario (SEU). Fue la única vez a lo largo de la dictadura que un movimiento de protesta consiguió terminar con una institución del régimen. El movimiento ofreció sustituirlo por el Sindicato Democrático de Estudiantes definido como: representativo, independiente, democrático, libre, autogestionado y autónomo. La reacción del régimen fue una gran campaña de represión académica, policial y jurídica, la cual se confrontó con manifestaciones de solidaridad. Durante mucho tiempo no faltaron nuevos participantes en la gran variedad de iniciativas estudiantiles puramente políticas, a través de asociaciones sociales variadas y hasta de eventos culturales. Entre los militantes más políticos iba emergiendo una cantidad enorme de grupos que pueden agruparse en tres categorías: marxistas-leninistas, trotskistas y, con menos presencia, anarquistas. En cada caso existían subgrupos, que seguían dividiéndose, y grupos mixtos. (CARRILLO-LINARES, 2015, p. 4975). 
Tanto por la campaña fuerte de represión de 1968 hasta 1973 como por las divisiones internas, al final de los años 60 el movimiento sufrió un declive. La idea de un sindicato democrático de estudiantes perdió fuerza, entre otras razones por los sucesos de 1968 y por la formación de grupos anticapitalistas. La radicalización de los grupos y disensiones internas que en algunos casos se alejaron de la sociedad civil hicieron que las organizaciones democráticas universitarias perdieron importancia y desaparecieran. Éstas fueron sustituidas por formas menos institucionalizadas. Además, a partir de 1968, de manera parecida a otros países, el debate sobre el modelo de universidad se abandonó centrándose en la toma del poder del estado. Así, se perdió el núcleo diferenciador del resto de la oposición al régimen. (ÁLVAREZ COBELAS, 2004, p. 343-357; GONZÁLEZ CALLEJA, 2009, p. 334-337).

A lo largo de los 70 , tanto por los procesos de cambio dentro del movimiento estudiantil como por la transformación política que se iba emergiendo en España, la protesta en las universidades iba descendiendo, pero todavía existían unos brotes relacionados con la política universitaria y, a la vez, con eventos políticos más amplios. Un ejemplo de ello lo tenemos en el curso 1974-1975, con la publicación del Decreto 2.925/1974 de 17 de octubre sobre la participación estudiantil, por el ministro Cruz Martínez Esteruelas. Según el nuevo decreto, los representantes de los estudiantes podían tomar parte en la elección y la gestión de los órganos de gobierno de la universidad y en la elaboración de los planes de estudio y los estatutos. (GONZÁLEZ CALLEJA, 2009, p. 352). Se trataba de un intento de poner en marcha los aspectos más liberalizadores de la reforma educativa de 1970 (LGE). Sin embargo, provoco un brote de protestas causando una fricción entre los militantes políticos que querían aprovechar la oportunidad y ejercer presión sobre las autoridades de la dictadura y grupos más extremistas que no lo vieron como una vía legitima. A finales de 1974 el movimiento se integró oficialmente en la oposición al pasar a manos de la Junta Democrática de España y de los partidos que la formaron. Durante los meses cruciales tras la muerte del dictador en diciembre 1975, el movimiento estudiantil se unió a la reivindicación generalizada por la ruptura democrática. Durante el proceso de reforma política puesto en marcha oficialmente con la Ley de reforma política, del 4 de enero 1977, la movilización estudiantil quedaba bastante marginada puesto que la universidad ya no tenía la importancia que poseía antes como un espacio casi ex-territorial para política. (GONZÁLEZ CALLEJA, 2009, p. 354-358).

El proceso de democratización del estado puso, por lo tanto, fin a la dimensión de resistencia al régimen en el que los estudiantes nunca llegaron a convertirse en una fuerza eficaz. (ÁLVAREZ COBELAS, 2004; GONZÁLEZ CALLEJA, 2009; HERNÁNDEZ SANDOICA, RUIZ CARNICER; BALDÓ LACOMBA, 2007). Sin embargo, el movimiento estudiantil en España tuvo una gran importancia en el panorama de la protesta contra el franquismo. De hecho, está considerado como uno de los elementos más relevantes que llevaron al desgaste de la dictadura y a la difusión de prácticas democráticas. Durante mucho tiempo hubo un debate sobre la contribución de la movilización social a la transición democrática. (GROVES et al, 2017; MOLINERO; YSAS, 1992; FOWERAKER, 1989). Hoy en día se acepta que, además del proceso de negociación llevado a cabo por las elites, la movilización social no solamente ejercía presión sobre los políticos para que tendieran hacia un sistema democrático, sino que, a nivel social y local, contribuyó al apoyo de la población para la democratización del estado y a la forja de nociones y rutinas cívicas 
democráticas. Sin embrago, el hecho que las elites jugaron un papel crucial con su negociación del consenso desde arriba frenó, en alguna medida, la creación de un sistema político que reflejara las aspiraciones de los movimientos sociales de empoderar a la sociedad con respecto al sistema político. Los Pactos de Moncloa de 1977 y la Constitución de 1978 expresan el consenso entre los herederos del franquismo y los representantes de la oposición, recientemente legalizada en el ámbito político. Se fijó en ellos la naturaleza de la democracia representativa de corte liberal que se establecía en España. Sin embargo, últimamente, un mayor número de investigadores apuntan que con este paso se quedaron fuera las aspiraciones de los movimientos sociales que contribuyeron al proceso de la transición desde abajo. (GROVES et al., 2017).

Otro debate relacionado con este anterior, relevante para nuestro análisis, es el de la naturaleza de la democracia que surgió en España tras la transición. En este sentido resulta interesante observar cómo, en diferentes ámbitos, la movilización social seguía tras la Constitución de 1978 en un intento por empujar hacia modelos democráticos diferentes al conseguido. (HERRERA, 2017). Siguiendo los movimientos de los Global Sixties, en España se advierten iniciativas que no se sintieron satisfechas con la democracia occidental y buscaron democratizar a la democracia. El movimiento estudiantil, a nivel global, perdió su empuje en este sentido a favor de los movimientos ecologistas y pacifistas.

Todos estos elementos de análisis fueron recogidos, de una manera u otra, por la prensa española de la época, en un intento de visibilizar la situación del país que, en esos momentos, se encontraba en situación de lucha para asentar unas bases de lo que sería el futuro como nación. De esta manera, en los siguientes apartados analizaremos cómo los medios de comunicación percibieron las políticas educativas del UCD, y en particular el tema de la autonomía universitaria, y la movilización del movimiento estudiantil que desafió el modelo político que se encontraba en la base de estas políticas educativas.

\section{La prensa y la autonomía universitaria}

La legislación con respecto a la cuestión universitaria se planteó seriamente incluso antes de la aprobación de la Constitución en diciembre 1978. El Proyecto de Ley de Autonomía Universitaria se debatió en el Consejo de Ministros el 27 de octubre de 1978, en el que se decidió enviar el Proyecto a las Cortes. El gobierno de la UCD tenía el reto de confrontar temas complejos en el tema universitario como el acceso a la universidad, las oposiciones y precariedad laboral del profesorado, y la evaluación, donde, de manera general, el nivel de la investigación en la universidad española era bajo. Desde otro punto de vista, el gobierno debía hacer frente a la oposición parlamentaria desde donde se denunciaba la falta de libertades y garantías democráticas en la institución. El proyecto de Ley de Autonomía Universitaria iba a ser la solución a todos estos retos. La intención del legislativo era otorgar a las universidades la capacidad de poder manejar mejor su situación interna, de manera que la autonomía se interpretó en tres claves: Autonomía estatutaria, que cubría el derecho de cada universidad de aprobar y redactar sus propios estatutos; Autonomía académica, referida a la capacidad de la universidad de desarrollar sus planes de estudio; y Autonomía presupuestaria, con la que se permitía elaborar sus propios presupuestos. (HERNÁNDEZ BELTRÁN, 2007, p. 368-375).

El proyecto de ley se encontró con un rechazo social y parlamentario amplio e intenso. Con respecto a la situación parlamentaria, el proyecto recibió un número tan 
elevado de enmiendas que hizo falta posponer la fecha de su presentación, fijada, finalmente, para el 1 de febrero 1980. El grupo parlamentario comunista denunció que carecía "de un contenido auténticamente transformador que permita modificar las viciadas estructuras y funcionamiento de la actual universidad". (HERNÁNDEZ BELTRÁN, 2007, p. 34). Las críticas vertidas por el grupo socialista se centraban en la falta de garantías del proyecto del carácter de servicio público de la institución universitaria y la ausencia de garantías de las libertades de sus miembros. Sin embargo, la mayoría de las enmiendas realizadas provinieron del grupo parlamentario del mismo gobierno - UCD -, que reclamaba un mayor número de derechos para el sector privado, entre otras reivindicaciones. Desde octubre de 1978, por lo tanto, hasta bien entrada la primavera de 1982, en la que fue retirado, se encontró el proyecto de ley en el medio de un agitado debate. (HERNÁNDEZ BELTRÁN, 2007).

De la revisión de las publicaciones del periódico El País se observa el claro posicionamiento de éste en contra del Proyecto de Ley de Autonomía Universitaria, donde se inciden en una serie de aspectos que se repiten en la mayor parte de artículos que explican el contenido de dicho proyecto. Los aspectos que con mayor frecuencia aparecen en los artículos, y que son los puntos que mayor oposición a la ley plantean, son los relacionados con la restricción del margen de autonomía de los Estatutos de las universidades y elaboración de planes de estudio; la estructura y selección del profesorado; y el tratamiento dado a las universidades privadas, fundamentalmente en cuanto a la financiación de éstas a cargo de la hacienda pública.

El inicio del interés del diario por la cercana realización de un proyecto de ley que regulara la Autonomía Universitaria para desarrollar la Ley General de Educación (1970) comienza con un artículo de Karmentxu Marín (27 de febrero de 1977). En él se hace mención a las informaciones vertidas sobre la futura realización del proyecto por parte del Ministerio de Educación previa encuesta de opinión a los estamentos implicados.

Estas informaciones coinciden en un momento donde las noticias anteriores ( 25 de enero de 1977; 8 de febrero de 1977; 22 de febrero de 1977) hacen referencia a las huelgas iniciadas por profesores no numerarios de universidad, de instituto y escuelas universitarias de formación del profesorado (PNN), bajo la petición de estabilidad en el empleo, la supresión de las oposiciones, un salario mínimo y autonomía y gestión democrática de los centros.

En el artículo de Marín (27 de febrero de 1977) se cuestiona si la autonomía será otorgada desde la Administración o si el Ministerio piensa contar con todos los estamentos implicados, anunciando, desde ese momento, que según el Ministerio los estudiantes quedarían fuera del proceso. El aislamiento de los estudiantes en el proceso constituyó una de las principales reivindicaciones que los movimientos estudiantiles realizaban durante las manifestaciones organizadas.

Marín destaca que las cuestiones principales que plantea el Ministerio al estudiar el decreto son la autonomía económica, la selección del profesorado y la elaboración de estatutos y planes de estudios, temas que son recurrentes en la oposición y críticas hacia el proyecto de ley recogidas por el diario a lo largo los siguientes años en sus publicaciones. De estas tres temáticas, el artículo desgrana las dudas y requerimientos que cada una de ellas plantea. De esta manera, presenta la encuesta realizada a representantes de los distintos sectores universitarios (profesorado, estudiantes y personal administrativo) 
recogiendo su opinión y ofreciendo información al ciudadano sobre los aspectos que debería contemplar el decreto; las directrices de una auténtica autonomía económica, de selección del profesorado y de elaboración de normas propias; y sobre los estamentos que deberían participar en la gestión de la Universidad.

Estas analíticas y esperanzadas declaraciones caen en el descontento cuando el 12 de julio de 1978 fue presentado el borrador del texto de la futura ley de Autonomía Universitaria en el pleno de la Junta Nacional de Universidades, poniendo fin a las especulaciones y controversias que durante el año anterior se habían sucedido. El País publicó, el día 14 de junio de ese mismo año, un resumen del proyecto de ley, y, en un reportaje del 12 de agosto, critica el secretismo con que había sido redactado, suponiendo una postura unilateral del partido en el gobierno.

En este reportaje, se recuerda que la intención del Ministerio al elaborar el borrador consistía en realizar una consulta a las universidades y a sus distintos estamentos; estudios de especialistas; y celebración de reuniones y seminarios entre expertos para aquellos aspectos más polémicos. Se critica la no presentación pública de los resultados a pesar de haberse realizado la encuesta, lo que se interpretó como que éstos ofrecían una respuesta de la universidad opuesta a los intereses del Ministerio. Y con ironía apuntan que "las reuniones, seminarios y consultas a expertos, si las hubo, quedaron en el secreto del sumario".

A lo largo de las ediciones del diario, se da la oportunidad de publicar artículos firmados por agentes afectados por la reforma, o entrevistas, principalmente, de aquellos con una postura claramente en contra de ella. Sin embargo, un artículo firmado por el Decano en funciones de la Facultad de Derecho de la Universidad Complutense, Luís Rodríguez, el 12 de enero de 1980 defiende la reforma, calificando al proyecto de "prudente" dadas la situación existente en el país que dificultan el hecho de "elaborar una ley válida para renovar toda la universidad". Para él, estas dificultades se encuentran derivadas de: (1) la peculiar estructura política y administrativa del nuevo Estado español; (2) la situación de la universidad en ese momento; y (3) la limitación de recursos políticos y económicos que presenta el legislativo.

A pesar de creer que no es una Ley totalmente adecuada ni definitiva, afirma que las numerosas críticas vertidas política y socialmente al proyecto de ley se deben a la coincidencia de la publicación de ésta con otros temas de actualidad como son: (1) las movilizaciones sociales ante el Estatuto de los trabajadores; (2) el despertar de los estudiantes ante el letargo post-franquista; (3) el proyecto de centros privados de enseñanza; y (4) la muerte de dos estudiantes durante las manifestaciones celebradas. Estos temas fueron aprovechados, según el Decano, para verter críticas hacia el ejecutivo y la Ley de Autonomía Universitaria.

El 1 de diciembre de 1981, el rotativo dedica un artículo a la Universidad de Navarra (universidad privada propiedad del Opus Dei) a la que dan voz. Aunque sus representantes no quisieron pronunciarse respecto al proyecto, indican que esta universidad

[...] espera que la ley de Autonomía Universitaria (LAU) le permita continuar con la labor docente iniciada en 1952, con la autonomía necesaria que la Constitución le garantiza, "y que no es sino una llamada a la responsabilidad". Desde esta perspectiva, la Universidad de Navarra estima que la autonomía debe llevar implícita 
la ayuda económica necesaria para los centros privados, sistema que se sigue en otros países "con los más diversos sistemas políticos". (GOÑl, 1981).

En el artículo describen su breve recorrido académico, las facultades y estudios que la componen, dedicando una parte amplia del mismo a las formas de financiación que presentan.

\begin{abstract}
El presupuesto de la universidad, según sus propios datos facilitados a EL PAIS, se financia por cuatro conductos: matrículas de los alumnos, ayudas del Estado, aportación de la Diputación Foral de Navarra y colaboración de la Asociación de Amigos de la Universidad de Navarra. Del Estado, la universidad recibió el curso pasado ayudas de dos tipos: una para gastos de capital, por la que percibió, con cargo a los Presupuestos Generales del Estado, diecisiete millones de pesetas, y otra, a través de ayudas a la investigación. (GOÑI, 1981).
\end{abstract}

En el artículo, además se hace mención del próximo debate sobre los Presupuestos Generales de Navarra, donde se debatiría una aportación a la Universidad de 320 millones de pesetas para que la Universidad de Navarra no recibiese una subvención directa por parte de la Diputación, si no entregada directamente, en forma de becas, a los alumnos navarros matriculados en este centro. En el propio artículo se apunta que esta era una posibilidad remota de que así sucediese.

La noticia publicada por Barcia (12 de diciembre de 1980) se refiere a la Comisión de Universidades e Investigación celebrada el día anterior centrándose en la discusión en torno al artículo 14 del proyecto de ley, en el que se matizan los derechos que implica el reconocimiento de las universidades privadas. Se incide en que no prosperó la enmienda por la que se prohibieran expresamente las subvenciones a las universidades privadas. Además, se incluye la referencia a las enmiendas otorgadas sobre "otorgar a las comunidades autónomas la potestad de crear universidades, asumiendo íntegramente su financiación por disposición normativa con fuerza de ley emanada de su asamblea legislativa". (BARCIA, 12 diciembre de 1980). Aprovecha para comentar la ruptura de la disciplina de voto entre los parlamentarios de UCD.

Entre las noticias también se recogen las divergencias en el seno del partido político en el gobierno entre socialdemócratas y democristianos (liberales y miembros del Opus Dei, como se expone en el propio artículo) por el carácter de "servicio público" de la Universidad. En él se hace constar que la votación entre los miembros es contra el proyecto gubernamental (5 de diciembre de 1980).

A pesar de que el periódico, como se puede ver, se posicionó en gran medida en contra de las políticas educativas de la UCD, sí intentó mantener una cobertura equilibrada, dejando espacio también a agentes sociales que apoyaban las iniciativas del gobierno. La afirmación que la iniciativa causo tanto resistencia, no tanto por su contenido, sino más bien por el contexto, deja apreciar como todos los factores involucrados en el debate: partidos políticos, medios de comunicación y el movimiento estudiantil estaban evaluando la ley como parte de una cuestión más amplia relacionada con la configuración política del país. Con respecto al movimiento estudiantil el hecho que el periódico se posiciono contra de la ley favoreció la cobertura de las movilizaciones estudiantiles dejándoles un amplio espacio para exponer sus ideas y su crítica, no solo hacia la ley sino hacia el desarrollo político llevado por la UCD. 


\section{El papel de los estudiantes en el proceso}

El proyecto de ley activó de nuevo la protesta estudiantil. Después de una temporada de baja actividad, en 1979 la protesta estudiantil aumentó su dinamismo llegando a ocupar el tercer lugar tras los sindicatos y las organizaciones de la extrema derecha, y ocupando el cuarto puesto, en cuanto a movilización crítica, en 1980. En los ochenta, la movilización estudiantil descendió de nuevo a los últimos lugares. (GONZÁLEZ CALLEJA, 2009, p. 358-359). Consultando la prensa diaria del momento, se puede apreciar que la lucha de los estudiantes fue presentada como un intento de profundizar el proceso democratizador del país y asegurar que éste se llevara a cabo, también, en el ámbito universitario. Los mensajes del movimiento sobre la ocupación de los espacios científicos por el poder del estado y sus representantes fueron reflejados en los artículos periodísticos:

[...] los estudiantes han pretendido estudiar, criticar, ofrecer alternativas para una Universidad, aunque no sigue un proceso paralelo con el intento de democratización del resto de las instituciones del pasado [...] estudiantes y profesores coincidieron en la exigencia de que dichos departamentos deben ser renovados, con objeto de conseguir el máximo grado de optatividad para la elaboración de los programas, los métodos de evaluación y la selección y control del professorado. (BARCIA, 1978).

Esta exigencia de los estudiantes de democratizar la institución se presentó como parte de una lucha mucho más amplia. De hecho, las protestas en el curso 1979-1980 coincidieron con el aumento en la conflictividad laboral tras la promulgación del Estatuto de los Trabajadores (aprobado y publicado en el Boletín Oficial del Estado el 10 de marzo de 1980), el aumento del paro y la ralentización en la reforma política. (GONZÁLEZ CALLEJA, 2009). Además, el movimiento estudiantil estableció alianzas con otros colectivos indignados con variados temas educativos.

El gobierno de la UCD estaba desarrollando en aquella época otra pieza de legislación educativa. La Ley Orgánica del Estatuto de Centros Escolares pretendía, basándose en las garantías de la Constitución, sancionar los derechos de la escuela privada no universitaria. Esta iniciativa, de manera parecida al proyecto de la LAU, movilizó a alumnos, padres y profesores, sin embargo, a diferencia de ésta, se llegó a promulgar en 1980, aunque en 1981 el Tribunal Constitucional estimó parcialmente el recurso de los senadores socialistas. A esas alturas, el gobierno de la UCD ya no tenía la capacidad de llevarlo a cabo y la iniciativa fue paralisada. (SEVILLA MORENO, 2016). Muchas de las protestas estudiantiles de esta época, por lo tanto, se hicieron en colaboración con otros colectivos contra la política educativa de la UCD. En diciembre 1979 encontramos la siguiente descripción:

La oposición a las leyes de Educación y de Universidades, pendientes de tramitación en las Cortes, constituyeron ayer el centro de las concentraciones, marchas, huelgas y asambleas de estudiantes de enseñanza media y universitaria en Madrid, La Coruña y Oviedo. (EL PAÍS, 8 de diciembre de 1979).

La reacción violenta por parte de las autoridades ocupaba bastante espacio en la descripción de los eventos. Entre ellas se encontraban las sucesivas protestas contra la disolución de los estudiantes por las fuerzas antidisturbios y las detenciones realizadas. De hecho, el 13 de diciembre se realizó un paro casi total en las universidades y 100,000 estudiantes participaron en la manifestación de Madrid por la mañana, acudiendo, por la 
tarde, a una marcha organizada por CCOO contra el Estatuto de los Trabajadores. La carga policial finalizó con la muerte de dos estudiantes ocasionando protestas, durante el resto del mes, contra dichos asesinatos. (GONZÁLEZ CALLEJA, 2009). En este sentido, la cobertura de la movilización alcanzó un tema de democratización mucho más amplio que el tema educativo. La reacción de la policía llevaba a los periodistas, en algunos casos, a hablar del reto de la libre expresión en el país y de la perenne percepción de los campus universitarios como campos de batalla, al menos a nivel de memoria colectiva. De todo ello se acusó directamente al gobierno por no aprender las lecciones del pasado.

Parece necesario señalar que la doctrina del Gobierno, expresada ya en anteriores ocasiones por su portavoz, sobre el carácter antidemocrático del derecho de manifestación, nos hace retroceder a los momentos más desagradables de nuestro inmediato pasado. ¿Por qué razón el derecho de reunión, reconocido en el artículo 21 de la Constitución, debe ser interpretado con criterios restrictivos? Nuestra norma fundamental establece que la autoridad solo podrá prohibir las manifestaciones cuando existan razones fundadas de alteración del orden público, con peligro para personas o bienestar. (EL PAÍS, 12 de diciembre de 1979).

Las protestas estudiantiles, en ese momento, fueron interpretadas en clave de la lucha por los derechos democráticos consagrados por la Constitución. Primero, como ya hemos expuesto, en relación con el proceso democratizador general. Y segundo, al estallar los conflictos, en relación con los derechos básicos conseguidos gracias al proceso de democratización. Sin embargo, el espíritu de la misma legislación fue, de igual manera, interpretado como antidemocrático, como se puede observar en esta cita que refleja las ideas del movimiento estudiantil:

Por otra parte, la ley trata de sancionar la financiación de los estudios a cargo de las tasas de matrícula y no de los Presupuestos Generales del Estado, lo que, en la práctica, equivale a negar el carácter público, estatal, de las universidades, introduciendo de una manera clara, dado que el sistema de becas es muy ambiguo, la discriminación clasista en la enseñanza superior. (...) La ley también permite y fomenta la privatización de sectores importantes de la universidad estatal y se contempla, en la misma, la creación de centros de enseñanza superior de carácter privado, a los que se les exime no ya de control parlamentario, sino del mínimo control social. (EL PAÍS, 15 de diciembre de 1979).

Se trata de críticas que coinciden con la tensión tradicional en España entre la idea de la libertad de enseñanza, defendida por la derecha, y el derecho de la educación, defendido por la izquierda política. La protesta se enfocó, por lo tanto, junto por el desarrollo de la Constitución en una dirección que ampliaba y fomentaba los derechos del sector privado en la educación. En este caso, en el ámbito universitario.

Además de protestar contra el contenido de la ley, el movimiento estudiantil criticó ampliamente el proceso de elaboración de la legislación. Los líderes de los estudiantes que recibieron la oportunidad de presentar sus ideas en las páginas del periódico aprovecharon el especio para reivindicar la importancia del movimiento como un actor social y la necesidad de asegurar un debate público en relación con la legislación educativa. En este sentido, el movimiento fue más allá de demandar la defensa de los derechos democráticos consagrados por la Constitución, reclamando un modelo democrático diferente al que se consiguió en España. Abogaron por un modelo más participativo en el cual los ciudadanos interesados constituyesen parte de los procesos, no solo de debate sino de legislación. Los 
líderes estudiantiles se refieren directamente a las relaciones entre movimientos sociales y parlamento:

Alguien se podrá preguntar: ¿Tiene acaso el movimiento estudiantil, o cualquier movimiento social, derecho a inmiscuirse en un terreno, el de la táctica en el Parlamento, que es competencia exclusiva de los partidos que están en él? (...) Los estudiantes reivindicamos un nuevo proceso democrático de elaboración de la LAU que cuente con participación universitaria, porque el seguido en esta ocasión nos ha marginado absolutamente. (DE LA PUERTA; CELADA CRESPO, 1980).

Se puede ver aquí los intentos del movimiento estudiantil de establecerse como un actor significativo en lo que refiere a las políticas educativas. Manifiestan la idea de disconformidad con las políticas educativas originadas desde las altas esferas de la política, así como la necesidad de involucrar directamente a los estudiantes, los profesores y la sociedad en su elaboración. De hecho, en un editorial publicado en El País (26 de febrero de 1980) se reconoce la importancia de los interesados - especialmente estudiantes y profesores - en frenar la política educativa de la UCD.

De un lado, el proyecto de ley de Autonomía Universitaria ha despertado entre los estudiantes y una buena parte del profesorado un gran rechazo, que ha impulsado a la oposición parlamentaria y a los partidos extraparlamentarios, siempre deseosos de encontrar base social para su sustentación política, a negar el pan y la sal a un texto que, pese a sus evidentes defectos e imperfecciones, merecía, sin embargo, algo más de análisis y bastantes menos impropérios. (EL PAÍS, 26 de febrero de 1980).

En este sentido, mientras la oposición parlamentaria y la oposición social llegaron a obstaculizar la política educativa de la UCD, a largo plazo, los estudiantes no llegaron a ocupar el papel protagonista que aspiraban en la dirección y gestión de las universidades. Como se puede apreciar el tema de la autonomía universitaria se percibía en clave del proceso democratizador. EI hecho que la UCD no sabía llegar a una fórmula más aceptable estaba relacionada por un lado por su manera de gestionar el tema y por el otro lado por el hecho que el modelo democrático que representaba no convencía ni a los partidos políticos de la izquierda ni a los movimientos sociales. La ley socialista aprobada, finalmente, (Ley de Reforma Universitaria, de 1983) se presentaba con muchas similitudes a la propuesta fracasada. Esta nueva reforma aprobada poco tiempo después disfrutaba del apoyo del grupo socialista con una presencia mayoritaria en el parlamento. Esta iniciativa reflejaba las aspiraciones de una gestión más democrática de la universidad. Precisamente esto fue un tema clave en la gestación de la ley. Los otros dos componentes de la autonomía universitaria: la académica y la presupuestaria se quedaron bastante limitadas. ${ }^{2}$ En muchos sentidos la ley socialista se parecía a la LAU, pero el hecho que encajaba mejor con los proyectos de democratización reclamados por la oposición de la izquierda la convirtieron en más aceptable, a pesar que, en realidad, se cerró con ella el sueño de una autentica autogestión de la institución universitaria.

\footnotetext{
2 Miguel Ángel Quintanilla (ponente de la comisión de educación y ciencia durante la gestación de la LRU) en una entrevista con las autoras (Salamanca, julio 2017).
} 


\section{Conclusiones}

Rotativos como El País, nacido sin presiones políticas, en un momento delicado de transición político-social, y comprometido con trasladar la realidad de la sociedad a los ciudadanos y con la movilización hacia el cambio, nos permiten analizar a través de sus artículos, espacios de opinión de línea editorial el movimiento estudiantil y sus reivindicaciones educativas.

Las movilizaciones estudiantiles, en España, tuvieron un resurgir a finales de los años 70 y principios de los 80 con protestas para lograr un cambio en la institución universitaria como parte de un proceso de cambio social mayor. En él se incluía la recuperación de los derechos civiles y, fundamentalmente, el fin de la dictadura, sin embargo, en el trasfondo se acometía una lucha por instaurar un tipo de democracia decididamente diferente a las democracias occidentales establecidas en Europa. Se trató de un movimiento que, si bien sus presiones no incidieron fuertemente en la finalización de la dictadura, sí lograron crear un clima de discrepancia en la sociedad y divulgar prácticas democráticas que hicieron tambalear al régimen. Sus movilizaciones se sucedieron a favor de la libertad de expresión y en contra de la excesiva ofensiva de las autoridades utilizada como freno a la reivindicación de dichas libertades.

El punto de mira de estas movilizaciones estudiantiles en el periodo que nos concierne, el Proyecto de Ley de Autonomía Universitaria fue, en sí, un gran avance para la reforma de la institución que durante tanto tiempo había permanecido adormecida, aunque con ella se abrió a la iniciativa privada. Los numerosos artículos publicados por $E /$ País ofrecieron a la opinión pública cuantiosos elementos de análisis sobre el proyecto de ley en una postura claramente opuesta a la del gobierno de la UCD.

La imposibilidad de llegar a su aprobación tuvo más que ver con cuestiones políticas y con la visión de cómo debía ser la democracia en España que con el contenido que en ella se trataba. Desde el punto de vista educativo, puede decirse que en el análisis de sus elementos no se encuentra tanta diferencia con la Ley de Reforma Universitaria que llegó a sancionarse con el cambio de legislativo. El momento histórico, las presiones políticas y el interés en establecer un estado democrático hicieron decantarse hacia la aprobación de una legislación sobre reforma de la autonomía universitaria diferente.

\section{Referencias}

ALMUIÑA, Celso. La opinión pública como motor de la transición española (1975-1982). In: QUIROSA-CHEYROUZE Y MUÑOZ, Rafael (Ed.). Prensa y democracia: Ios medios de comunicación en la transición. Madrid: Biblioteca Nueva, 2009. p. 29-44.

ÁLVAREZ COBELAS, José. Envenenados de Cuerpo y Alma: La oposición universitaria en Madrid (1939-1970). Madrid: Siglo XXI, 2004.

ARIAS BALSA, Iván. Revisión histórico-jurídica del principio de autonomía universitaria y su relación con la existencia de elecciones en el seno de la universidad. Dereito, 21 (1), p. 99-149, 2012.

BARCIA, Esteban. Los estudiantes, entre el escepticismo y la posibilidad de la reforma. EI País, 21 enero 1978. Disponible en:

<http://elpais.com/diario/1978/01/21/sociedad/254185207_850215.html>. Acceso en: 19 abr. 2017.

BARRERA, Carlos. Poder político, empresa periodística y profesionales de los medios en 
la transición española. Comunication and Society, 10 (2) p. 7-46, 1997.

BARRERA, Carlos; ZUGASTI, Ricardo. La introducción de los valores democráticos en la prensa de la transición española (1975-1978). In: BENAVIDES, J.; FERNÁNDEZ, E.

(Eds.). Valores y medios de comunicación. Madrid: Edipo, 2001. p. 109-138.

BAZÁN, Francisco. Editorialismo electoral durante la Transición: La Vanguardia, EI País y Diario 16. Valladolid: Ediciones Universidad de Valladolid, 2015.

CÁMARA VILLAR, Gregorio. La autonomía universitaria en España hoy, entre el mito y la realidad. Revista Catalana de Dret Public, 44, p. 67-109, 2012.

CARRILLO-LINARES, Alberto. Subversivos y malditos en la universidad de Sevilla (1965-1977). Sevilla: Centro de Estudios Andaluces, 2008.

. Universidades y transiciones políticas: el caso español en los años 60-70.

Espacio, Tiempo y Educación, v. 2, n. 2, 2015.

CAGNOLATI Antonela. Ma che colpa abbiamo noi? Mass-media e protesta studentesca. In: BETTI, C.; CAMBI, F. (Eds.). II '68: Una rivoluzione culturale tra pedagogia e scuola. Milano: Edizioni Unicopli, 2011.

COMISION DE LA ASAMBLEA DE PNN DE DERECHO. Los PNN o una alternativa para la Enseñanza. El País, 22 febrero 1977. Disponible en:

<http://elpais.com/diario/1977/02/22/sociedad/225414011_850215.html>. Acceso en: 4 abr. 2017.

CRUZ RUIZ, Juan. Una memoria de "EI Pais": 20 años de vida en una redacción (1 ed.). Barcelona: Plaza \& Janés, 1996.

DE LA PUERTA, Javier; CELADA CRESPO, Juan. El movimiento estudiantil, por la retirada de la ley de Autonomía Universitaria. El País, 1 febrero 1980. Disponible en: <http://elpais.com/diario/1980/02/01/espana/318207601_850215.html>. Acceso en: 7 abr. 2017.

DECRETO 2.925/1974 de 17 de octubre sobre participación estudiantil. Boletín Oficial del Estado. Madrid, 22 de octubre de 1974, n. 253, p. 21441-21442.

DELLA PORTA, Donatella; DIANI, Mario. Social movements, an introduction, second edition. Oxford: Blackwell Publishing, 2006.

DOMĖNECH SAMPERE, Xavier. Clase obrera, antifranquismo y cambio político: pequeños grandes cambios, 1956-1969. Madrid: Los Libros de la Catarata, 2008.

El próximo curso será decisivo para la autonomía universitaria. El País, 12 agosto 1978. Disponible en: <http://elpais.com/diario/1978/08/12/sociedad/271720813_850215.html>. Acceso en: 4 abr. 2017.

FOWERAKER, Joe. Making Democracy in Spain: Grass-roots Struggle in the south, 1955-1975. Cambridge: Cambridge University Press, 1989.

GONZÁLEZ CALLEJA, Eduardo. Rebelión en las aulas: movilización y protesta estudiantil en la España contemporánea, 1865-2008. Madrid: Alianza editorial, 2009.

GOÑI, Fermín. La autonomía debe llevar implícita la subvención, según la Universidad de Navarra. El País, 1 diciembre 1981. Disponible en:

<http://elpais.com/diario/1981/12/01/sociedad/376009210_850215.html>. Acceso en: 5 abr. 2017.

GROVES, Tamar; TOWNSON, Nigel; OFER, Inbal; HERRERA, Antonio. Social Movements and the Spanish Transition Building Citizenship in Parishes, Neighbourhoods, Schools and the Countryside. London: Palgrave Mcmillan, 2017. 
HERNÁNDEZ BELTRÁN, Juan Carlos. Parlamento y universidad en la transición a la democracia (1975-1982). El proyecto de ley de Autonomía Universitaria: radiografía de un desencuentro. Historia de la educación, v. 26, p. 367-391, 2007.

HERNÁNDEZ HUERTA, Jose Luis; GONZÁLEZ GÓMEZ, Sara. Opinión pública y educación durante la transición a la democracia en Argentina. Primeras consideraciones y guía de fuentes documentales. Educació i història: Revista d'història de l'educació, 24, p. 173-215, 2014.

HERNÁNDEZ HUERTA, Jose Luis; ORTEGA GAITE, Sonia. Civic Education and public opinion in Argentina during the transition to democracy (1982-1983). History of

Education \& Children's Literature, 10 (2), p. 359-389, 2015.

HERNÁNDEZ SANDOICA, Elena; RUIZ CARNICER, Miguel Ángel; BALDÓ LACOMBA, Marc. Estudiantes contra Franco (1939-1975): oposición política y movilización juvenil. Madrid: La esfera de los libros, 2007.

HERRERA, Antonio. Citizenship and Democracy in the Spanish Countryside. In: GROVES, Tamar; TOWNSON, Nigel; OFER, Inbal; HERRERA, Antonio. Social

Movements and the Spanish Transition. Palgrave Studies in the History of Social Movements. London: Palgrave Macmillan, 2017. p. 97-123.

HILWIG, Stuart. Italy and 1968: Youthful unrest and democratic culture. Basigstoke: Palgrave, 2009.

HOEFFERLE, Caroline. British student activism in the long sixties. v. 9. New York: Routledge, 2012.

KLIMKE, Martin. The Other Alliance: Student Protest in West Germany and the United States in the Global Sixties. Princeton: Princeton University Press, 2011.

La universidad, de nuevo. El País, 2 de diciembre de 1979. Disponible en: <http://elpais.com/diario/1979/12/12/opinion/313801202_850215.html>. Acceso en: 8 abr. 2017.

LINZ, Juan José. Totalitarian and authoritarian regimes. Colorado: Lynne Rienner Publishers, 2000.

Los estudiantes quieren que se les oiga. El País, 15 de diciembre de 1979. Disponible en: <http://elpais.com/diario/1979/12/15/opinion/314060402_850215.html>. Acceso en: 18 abr. 2017.

Los no numerarios de universidad entran también en huelga. El País, 25 de enero de 1977. Disponible en:

<http://elpais.com/diario/1977/01/25/sociedad/222994803_850215.html>. Acceso en: 4 abr. 2017.

Los PNN de universidad discutirán si hacen los exámenes de febrero. El País, 8 de febrero de 1977. Disponible en:

<http://elpais.com/diario/1977/02/08/sociedad/224204402_850215.html>. Acceso en: 4 abr. 2017.

MARAVALL, José. María. Dictadura y disentimiento político: obreros y estudiantes bajo el franquismo. Madrid: Ediciones Alfaguara, 1978.

MARÍN, Karmentxu. La Autonomía Universitaria es inseparable de una gestión democrática. El País, 27 de febrero de 1977. Disponible en:

<http://elpais.com/diario/1977/02/27/sociedad/225846007_850215.html>. Acceso en: 4 abr. 2017.

MARINA, Marcos. Prensa española y transición (1975-1982). In: IBARRA 
AGUIRREGABIRIA, Alejandra (Coord.). No es país para jóvenes, Actas del III Encuentro de jóvenes investigadores de la AHC. Vitoria-Gasteiz: Universidad del País Vasco, 2012.

MELUCCI, Alberto. The symbolic challenge of contemporary movements. Social research, p. 789-816, 1985.

MOLINERO, Carme; YSAS, Pere. Movimientos sociales y actitudes políticas en la crisis del franquismo. Historia Contemporánea 8, p. 269-279, 1992.

MONTERO, Mercedes; RODRÍGUEZ-VIRGILI, Jordi; GARCÍA-ORTEGA, Carmela. La construcción mediática de la comunidad política. La prensa en la transición española a la democracia. Palabra clave, 11 (2), p. 293-309, 2008.

NOGUEIRA, Rosario. Principios Constitucionales del Sistema Educativo Español. Madrid: Centro de Publicaciones. Ministerio de Educación y Ciencia, 1988.

QUIROSA-CHEYROUZE Y MUÑOZ, Rafael (Ed.). Prensa y democracia: los medios de comunicación en la transición. Madrid: Biblioteca Nueva, 2009.

RODRÍGUEZ RAMOS, Luís. Autonomía Universitaria en España. EI País, 12 de enero de 1980. Disponible en:

<http://elpais.com/diario/1980/01/12/sociedad/316479601_850215.html>. Acceso en: 4 abr. 2017.

RUBIO MAYORAL, José Luís. Sobre los modelos de universidad en la política educativa de la Transición española. Herencia y génesis de sus bases (1976-1982). Espacio, Tiempo y Educación, 2 (2), p. 125-153, 2015.

RUIZ GONZÁLEZ, David. Historia de comisiones obreras (1958-1988). Madrid: Siglo $\mathrm{XXI}, 1994$.

SÁNCHEZ LEÓN, Pablo. Radicalism without Representation: On the Character of Social Movements in the Spanish Transition to Democracy. In: ALONSO, G.; MURO, D. The Politics and Memory of Democratic Transition. The Spanish Model. New York: Routledge, 2010. p. 95-112.

SAZ, Ismael. Fascismo y Franquismo. Valencia: Universidad de Valencia, 2004.

SEOANE, Cruz; SUEIRO SEOANE, Susana. Una historia de El País y del Grupo Prisa. Barcelona: Plaza \& Janés Editores, 2004.

Se generalizan las protestas estudiantiles contra los proyectos de ley de educación y universidades. EI País, 8 de diciembre de 1979. Disponible en:

<http://elpais.com/diario/1979/12/08/espana/313455622_850215.html>. Acceso en: 12 abr. 2017.

SEVILLA MORENO, Diego. La difícil traslación a una política de gobierno de un acuerdo constitucional forzado. La Unión de Centro Democrático y su malograda Ley Orgánica del Estatuto de Centros Escolares (LOECE) de 1980. Historia y Memoria de la Educación, v. 3, p. 45-70, 2016.

SUEIRO SEOANE, Susana. El papel del Diario "EI País" en la transición. In: QUIROSACHEYROUZE Y MUÑOZ, Rafael (Ed.). Prensa y democracia: los medios de comunicación en la transición. Madrid: Biblioteca Nueva, 2009. p. 151-162.

Un ministro entre dos fuegos. El País, 26 de febrero de 1980. Disponible en: <http://elpais.com/diario/1980/02/26/opinion/320367609_850215.html>. Acceso en: 13 abr. 2017.

ZUGASTI, Ricardo. La forja de una complicidad: monarquía y prensa en la transición 
española (1975-1978). Madrid: Fragua, 2007.

TAMAR GROVES es Profesor Contratado Doctor en la Universidad de Extremadura. En los últimos cinco años ha publicado seis libros en editoriales españoles y extranjeras, entre ellas Routledge y Palgrave Macmillan. Ha publicado también en revistas prestigiosas como European History Quarterly, Journal of Social History, History of Education, Paedagogica Historica: International Journal of the History of Education, European Journal of Higher Education, etc. Es especialista en história de la renovación pedagógica, mujer y educación superior, y ciudadanía y educación. Actualmente trabaja sobre transferencia educativa y formación del profesorado.

Endereço: Avda. Universidad, s/n - 10003 - Cáceres/Extremadura - España.

E-mail: tamargroves@unex.es

MARIA INMACULADA PEDRERA RODRÍGUEZ es Doctora en Pedagogía por la Universidad de Extremadura y profesora de Teoría e Historia de la Educación en la misma universidad. Pertenece a los grupos de Investigación reconocidos de Eduinnovagogía (HUM 971) y Nodo Educativo (SEJ 035). Su línea de investigación principal es la Educación emocional, y de forma conjunta ha desarrollado investigaciones en el ámbito de la Historia de la Educación. Contribuye con editoriales de reconocido prestigio. Ha publicado en la International Journal of Educational Research and Innovation y, en los últimos años, ha participado en numerosos congresos y workshop de carácter internacional. Es miembro de asociaciones científicas de desarrollo profesional docente y miembro de comités científicos de alcance internacional. Endereço: Avda. Universidad, s/n - 10003 - Cáceres/Extremadura - España.

E-mail: inmapedrera@unex.es

Recebido em 05 de outubro de 2017.

Aceito em 28 de novembro de 2017. 